\title{
Paucity of mobile species on constructed seawalls: effects of urbanization on biodiversity
}

\author{
M. G. Chapman* \\ Centre for Research on Ecological Impacts of Coastal Cities, Marine Ecology Laboratories A11, University of Sydney, \\ Sydney, New South Wales 2006, Australia
}

\begin{abstract}
Intertidal seawalls are increasingly being built in urban estuaries, fragmenting and replacing natural intertidal shores. Many species of animals and plants live on seawalls. Previous work in Sydney Harbour has shown that common species live on seawalls and rocky shores, but vary in their relative abundances according to height on the shore and location. The potential value of seawalls to provide viable intertidal habitat will depend on their ability to support the full diversity of intertidal species, including those that are relatively rare. This study examines the diversity of animals and plants at 2 heights on rocky shore and seawalls, at 4 locations in Sydney Harbour, using presence/absence measures in an intensive sampling schedule in each habitat. The total number and types of taxa found were very variable within and among locations, but clear patterns arose when the data were combined (800 quadrats in each habitat). With few exceptions, algae and sessile animals were similarly distributed across habitats, but approximately $50 \%$ of the mobile animals were not found on seawalls. In addition, rocky shores had a greater proportion of rare taxa (only found in 1 or very few quadrats). Of the shared taxa, patterns of occurrence were similar on the 2 structures. Potential reasons for these patterns are discussed and ways to improve seawalls as a habitat for mobile animals are proposed.
\end{abstract}

KEY WORDS: Artificial structures · Assemblage · Diversity · Habitat · Intertidal · Seawall · Urbanization

Resale or republication not permitted without written consent of the publisher

\section{INTRODUCTION}

With continued growth of the human population and more crowding into urban centres (Alig \& Healy 1987), ecologists and environmental managers have to work out ways to maintain biodiversity and ecological processes in increasingly disturbed, altered and degraded surroundings (e.g. Rebele 1994, McDonnell et al. 1997, Niemelä 1999a,b, Underwood \& Chapman 1999, Savard et al. 2000). Urbanization not only removes and fragments natural habitats (Niemelä 1999b, Saunders \& Briggs 2002) and adds pollutants to the air (e.g. Tyler 1975, McDonnell et al. 1997) and waterways (e.g. Gray et al. 1988, Gray 1989, Peterson et al. 1996, Stark 1998, Squires \& Lesack 2001), but also results in a number of new structures, e.g. roads, buildings, docks, etc., being added to the environment (e.g. Whitney \& Adams 1980, Eversham et al. 1996, Burdick \& Short 1999, Con- nell 2000). These novel structures can be composed of natural materials, e.g. local rock, or of manufactured material, e.g. cement, macadam, glass. Although much research on the effects of urbanization in terrestrial habitats has focused on habitat-fragmentation (Eversham et al. 1996, Bastin \& Thomas 1999), the addition of newly built structures has also been shown to strongly affect the abundances and diversity of species. Such changes to habitat may have positive (e.g. Eversham et al. 1996, Bastin \& Thomas 1999) or negative effects on different taxa (e.g. Whitney \& Adams 1980, Blair 1996).

In coastal marine environments, much of the emphasis on effects of urbanization has been on the effects of toxic spills or urban runoff (Short \& Burdick 1996, Inglis \& Kross 2000), sewage (e.g. Chapman et al. 1995, Nixon 1995, Smith et al. 1999), nutrients (Vidal et al. 1999, Campbell 2001) or other water-borne contamination (Bryan et al. 1986), collection of animals to use as 
food or bait (van Herwenden et al. 1989, Kingsford et al. 1991) or use of the waterways for commercial or recreational boating (Walker et al. 1989, Burdick \& Short 1999, Bell et al. 2002, Widmer et al. 2002). There has been relatively little emphasis on replacement or loss of natural habitat by built structures. Notable exceptions are fragmentation and loss of mangroves and estuarine wetlands (e.g. Zedler 1996) (which, although tidal, superficially resemble terrestrial habitats) and seagrasses (see Duarte 2002 for review).

Nevertheless, many novel structures have also been added to inshore waters, e.g. infrastructure for shipping and recreational boating (Walker 1988, Burdick \& Short 1999, Connell \& Glasby 1999, Bulleri et al. 2000, Connell 2000), for aquaculture activities (Gilbert et al. 1997), or materials for the stabilization of 'soft' shorelines (Johannesson \& Warmoes 1990, Davis et al. 2002). Such novel structures may replace natural habitats, add to the length of the shoreline (Thompson et al. 2002) or provide additional hard surfaces to areas of an estuary where natural hard substrata may be absent or sparse.

Intertidal seawalls are some of the most common structures in many urbanized estuaries. For example, more than $50 \%$ of the shoreline of Sydney Harbour (Fig. 1) is composed of intertidal seawalls (author's unpubl. data). The walls are not continuous, being separated by beaches and rocky headlands. Individual walls are 10 s of metres to many kilometres long. They vary in composition (sandstone, cement, metal) and between having a very smooth surface to being relatively complex topographically (e.g. sandstone 'dry' walls without a cement matrix). Composition and surface complexity have been shown to influence intertidal and subtidal assemblages (Raimondi 1988, McGuinness 1989), including those that live on built structures (e.g. Glasby 2000). Nevertheless, despite their individual variability, seawalls in Sydney Har-

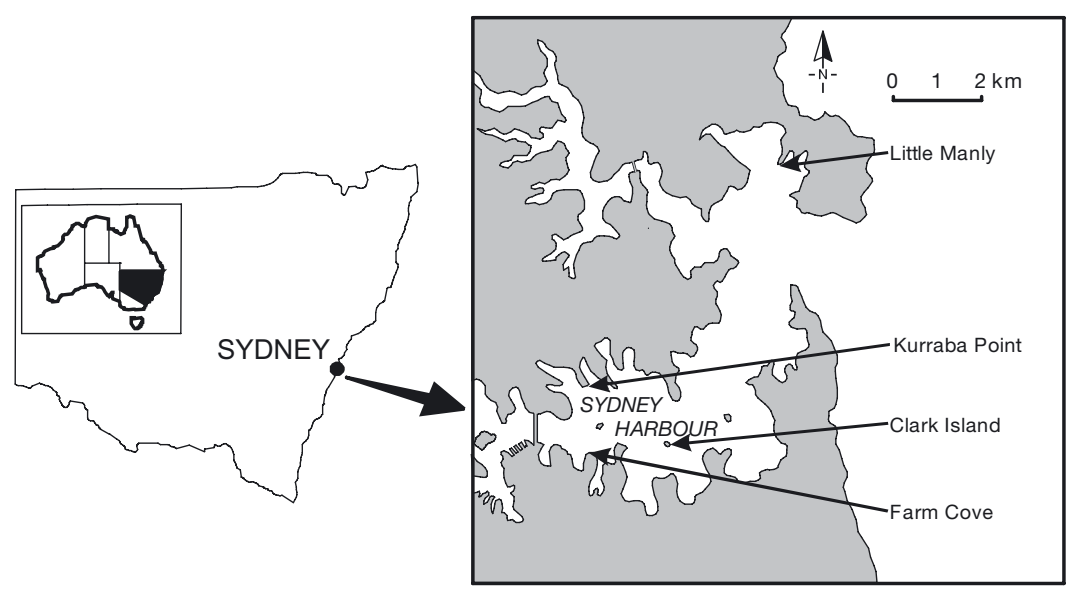

Fig. 1. Location of study sites in Sydney Harbour, New South Wales, Australia bour have 3 common features in which they all differ from most local natural intertidal shores.

First, seawalls are generally vertical, or very steeply sloping. This contrasts markedly with most natural rocky shores in and around Sydney, which are nearhorizontal or gently sloping over most of the intertidal range. Many intertidal and subtidal organisms have been shown to be strongly influenced by the slope of the substratum (Whorff et al. 1995, Gabrielle et al. 1999). For example, on subtidal reefs, sessile invertebrates tend to be more abundant, diverse and occupy more space on vertical walls (e.g. Wendt et al. 1989). Whorff et al. (1995) showed that the invertebrates and algal epiphytes associated with intertidal algal turfs were strongly influenced by slope of the substratum, possibly because of the amount of sediment trapped in the algal fronds. These patterns also varied with tidal height.

Second, the spring tidal range in Sydney Harbour is approximately $2 \mathrm{~m}$, which provides a maximal intertidal extent of just over $2 \mathrm{~m}$ on a vertical wall, depending on the amount of splash (e.g. from boating) and wave-action. The gentle slope of many natural rocky shores provides an intertidal extent of 10 s of metres. Therefore, the available intertidal area on seawalls is just a fraction of that available on natural shores. Again, studies have demonstrated a positive relationship between the size of a patch of intertidal habitat and the abundance and diversity of species living in it (e.g. Hawkins \& Hartnoll 1980, McGuinness 1984). Therefore, the reduced available area of intertidal habitat on a seawall may limit the number of species living on it.

Third, on intertidal shores, species diversity increases with the range and availability of different habitats (e.g. McGuinness \& Underwood 1986, Archambault \& Bourget 1996, Thompson et al. 1996), particularly habitats that retain water or moisture during low tide (e.g. overhangs, crevices and rock-pools; Astles 1993). Although seawalls may have shallow cracks between adjacent stones, habitats such as rock-pools are generally absent, except in areas where the seawalls are degraded and have slumped. These may contain small, shaded crevices that retain water during low tide. These habitats are, however, frequently removed during repairs to seawalls (author's pers. obs.).

The reported similarity between the intertidal organisms that occupy artificial hard surfaces and natural shores has led to conclusions that artificially constructed hard surfaces may simply 
add to the extent of intertidal rocky habitat, with any effect being to increase rather than decrease connectedness of patches of this habitat (Thompson et al. 2002). A preliminary quantitative survey on seawalls and natural reefs in Sydney Harbour has, however, shown that assemblages differed between shores and artificial seawalls, although this varied according to intertidal height, the slopes of the shore and the location in the harbour (Chapman \& Bulleri 2003). Chapman \& Bulleri (2003) measured abundances and cover of macroflora and macrofauna in replicate quadrats in different sites in each habitat (rocky shores and seawalls). Few species were confined to a single habitat and differences between habitats were primarily due to the relative abundances of a few taxa.

Observations suggested, however, that some species (particularly some larger gastropods, whelks and starfish) were seldom seen on seawalls, although they occurred relatively sparsely on rocky shores within the harbour. Although quantitative sampling using 5 quadrats per site in replicate sites (as used by Chapman \& Bulleri 2003) is adequate to identify spatial differences and temporal changes in intertidal assemblages on wave-exposed and sheltered shores around Sydney (e.g. Underwood 1981, Underwood \& Chapman 1998), this intensity of sampling does not necessarily sample sparse species (as indicated for intertidal boulders; Chapman 2002). Therefore, to test the model that seawalls do not support the same diversity of intertidal organisms as natural rocky shores in Sydney Harbour, the present study sampled large numbers of quadrats in each habitat. These covered much larger areas of each habitat than traditionally sampled in order to maximize the number of species found. As this was fairly time-consuming, data were necessarily reduced to presence/absence, thus comparing the number of taxa found, without comparisons of relative abundances of the different taxa. Sampling was restricted to mid- and low-shore levels because few species were found in the 2 habitats high on the shore.

Observations also suggested that there were more species which were sparse on rocky shores and that most species on seawalls were widespread and common. If seawalls cannot support sparsely distributed species, replacement of rocky shores by these artificial structures could have large deleterious effects on the species assemblage. Therefore, the hypothesis was also proposed that a greater proportion of the taxa on rocky shores would be found in only a few quadrats, i.e. shores would have a greater proportion of sparse taxa than would seawalls.

In addition, although different seawalls varied in composition and construction, each seawall appeared to be relatively consistent along its length. Nearby rocky shores showed differences in slope and topo- graphic complexity at scales from metres to 10 s of metres. Because species diversity can increase with increasing variability in the physical environment, the model was also proposed that there would be fewer species on rocky shores when samples were arranged over a shorter length of shore, compared to the same intensity of sampling when quadrats were spaced over a greater distance. On seawalls, in contrast, it was predicted that similar numbers of species would be found in both sampling schemes, because the physical structure of the seawalls showed little variation along their lengths. Each habitat was therefore sampled with equal numbers of quadrats spaced across different lengths of seawall or shore, in order to test the hypothesis that the number of taxa sampled using the same sampling intensity over different lengths of habitat would differ between rocky shores and seawalls.

The 2 habitats were sampled in 4 locations around the Harbour to test the hypothesis that differences between species occurrence on seawalls and rocky shores would reflect a similar pattern among locations.

\section{MATERIALS AND METHODS}

Assemblages were sampled at each of 4 locations in Sydney Harbour: Farm Cove, Clark Island, Kurraba Point and Little Manly (Fig. 1). These locations were selected because they had a relatively undisturbed sandstone rocky shore adjacent to a seawall built of quarried sandstone blocks and each was long enough for the proposed sampling design. Seawalls and shores were sampled in the same locations so that the models could be evaluated for different areas around the Harbour. Low-shore and midshore intertidal assemblages were identified on the seawall. The former occurred immediately above LWST (low water spring tide) and was characterized by extensive cover of foliose algae and the tubiculous polychaete Galeolaria caespitosa. The mid-shore assemblage was $50 \mathrm{~cm}$ above this and was characterized by limpets, barnacles and encrusting algae. The vertical extent of different assemblages on seawalls is small because of the relatively small tidal range in Sydney Harbour. Although only separated by $50 \mathrm{~cm}$, these assemblages were easy to distinguish consistently among locations. Similar assemblages on the rocky shores were more extensive, and they were therefore sampled in the middle of the extent of each assemblage.

Each habitat at each location was sampled using 100 quadrats, $30 \mathrm{~cm}$ long and $25 \mathrm{~cm}$ high. Where possible, these were sampled contiguously across $24 \mathrm{~m}(80$ quadrats) and then a further 20 were sampled after a gap of $12 \mathrm{~m}$. This allowed tests of the hypothesis that the number of species found in 60 contiguous quadrats 
across $18 \mathrm{~m}$ of habitat (Quadrats 1 to 60) would be smaller than those found in 60 quadrats spaced in 3 sets of $6 \mathrm{~m}$, each separated by $12 \mathrm{~m}$ (i.e. Quadrats 1 to 20,61 to 100) on rocky shores, but not on seawalls. Where the walls or the shores did not allow for that sampling scheme, 100 quadrats were taken contiguously (in which case, Quadrats 1 to 60 [18 m] were compared with 1 to 20,41 to 60 and 81 to 100 [30 m]), or gaps between sets of 20 quadrats were left where feasible. In each quadrat, all organisms visible to the naked eye were noted.

\section{RESULTS}

Altogether, 139 taxa were found; 107 on seawalls and 127 on shores. Most taxa were identified to species or morphospecies (i.e. consistently, although not formally identified, sensu Oliver \& Beattie 1996), except for some filamentous, small foliose or encrusting algae, which were grouped into informal categories (e.g. green filaments, small red algal complex, nongeniculate corallines) and some sessile animals, e.g. spirorbid polychaetes.

Patterns of diversity varied from height to height interactively among shores, with no generality of patterns $\left(\right.$ ANOVA, Location $\times$ Habitat $\times$ Height, $F_{3,1584}=$ 47.10, p < 0.001; all pair-wise comparisons between habitats were significant using Student-NewmanKeuls [SNK] tests). There were significantly more species per quadrat on the seawall than on the rocky shore in 4 comparisons and the reverse patterns was found in the other 4 (Table 1a). There was no generality according to height on the shore for these significant differences.

The total number of taxa found in 100 quadrats was compared between habitats for each height and location separately using $\chi^{2}$ tests. When all data were combined, the number of taxa on seawalls (107) was not significantly different from the number on rocky shores (127). Nevertheless, the number of taxa was generally smaller on each seawall than on the equivalent rocky shore, except for the mid-shore level at Kurraba Point and the low-shore level at Farm Cove (although the $\chi^{2}$ test was only significant for the mid-shore at Little Manly, Table 1b).

There were also clear differences in the types of taxa found in the 2 habitats (data combined across heights and shores; Table 1c), although again, this pattern was not clear when the different heights in the different locations were examined separately. Overall, the numbers of types of encrusting, foliose and filamentous algae were similar between seawalls and rocky shores, with few algae uniquely found in only one of the habitats. Although nearly half of the sessile animals identified were only found on the seawalls or on the shores (i.e. 19 of the 42 taxa), similar numbers were unique to each habitat and, therefore, overall diversity of sessile animals was similar between habitats. Most of the taxa unique to seawalls were bryozoans and sponges, while most of those unique to rocky shores were sea anemones and other sponges.

The mobile animals included starfish, molluscs, sipunculids, platyhelminths and 1 species of sea urchin. Numbers of species of mobile animals differed markedly between habitats, with $95 \%$ of the 43 species found on rocky shores, $46 \%$ uniquely so. Only 2 species, the fissurellid limpet Tugali cicatricosa and the pulmonate Onchidium damelii, were found on seawalls alone. The mobile animals found only on rocky shores included a range of types: grazing snails, predatory whelks, starfish, the sea urchin, sipunculids, limpets and chitons.

To test the hypothesis that the frequency of occurrence (i.e. the number of quadrats in which each taxon was found) was dissimilar across habitats, with more species on rocky shores found in fewer quadrats, the proportion of taxa found in less than 10, 11-20, 21-30, $31-40,41-50,51-100,101-200 \ldots \ldots . .701-800$ quadrats (summed over all shores and both heights) were com-

Table 1. (a) Mean (SE) number of taxa per quadrat; ${ }^{*}$ : significant difference using Student-Newman-Keuls (SNK) tests after ANOVA at $\mathrm{p}<0.05$ (see text), (b) total number of taxa across 100 quadrats for each height on each wall; ${ }^{*}$ : significant $\chi^{2}$ test at $\mathrm{p}<0.05$, and (c) total number of taxa and number unique to each habitat for encrusting algae, a mix of foliose (fol.) and filamentous (fil.) algae, mobile animals and sessile animals

\begin{tabular}{|lccccc|}
\hline & \multicolumn{2}{c}{ Mid-shore } & \multicolumn{2}{c|}{ Low-shore } \\
& Seawall & Shore & Seawall & Shore \\
\hline a & & & & \\
Clark Island & $13.07(0.29)$ & $14.36(0.29)^{*}$ & $14.63(0.38)$ & $18.15(0.26)^{*}$ \\
Farm Cove & $16.62(0.28)$ & $13.68(0.36)^{*}$ & $16.12(0.33)$ & $11.78(0.31)^{*}$ \\
Kurraba Point & $20.98(0.28)$ & $14.83(0.35)^{*}$ & $14.09(0.23)$ & $15.13(0.28)^{*}$ \\
Little Manly & $15.92(0.27)$ & $17.00(0.35)^{*}$ & $18.65(0.26)$ & $17.77(0.35)^{*}$ \\
b & & & & \\
Clark Island & 48 & 53 & 68 & 85 \\
Farm Cove & 47 & 55 & 69 & 55 \\
Kurraba Point & 56 & 51 & 50 & 64 \\
Little Manly & 44 & $65 *$ & 65 & 84 \\
& & & & \\
& & & & & \\
Seawall & Seawalls only & Shore & Shores only \\
c & 6 & 0 & 6 & 0 \\
Encrusting algae & 37 & 1 & 40 & 4 \\
Fol./fil. algae & 37 & 2 & 42 & 10 \\
Mobile animals & 23 & 9 & & \\
Sessile animals & 41 & & & & \\
\end{tabular}



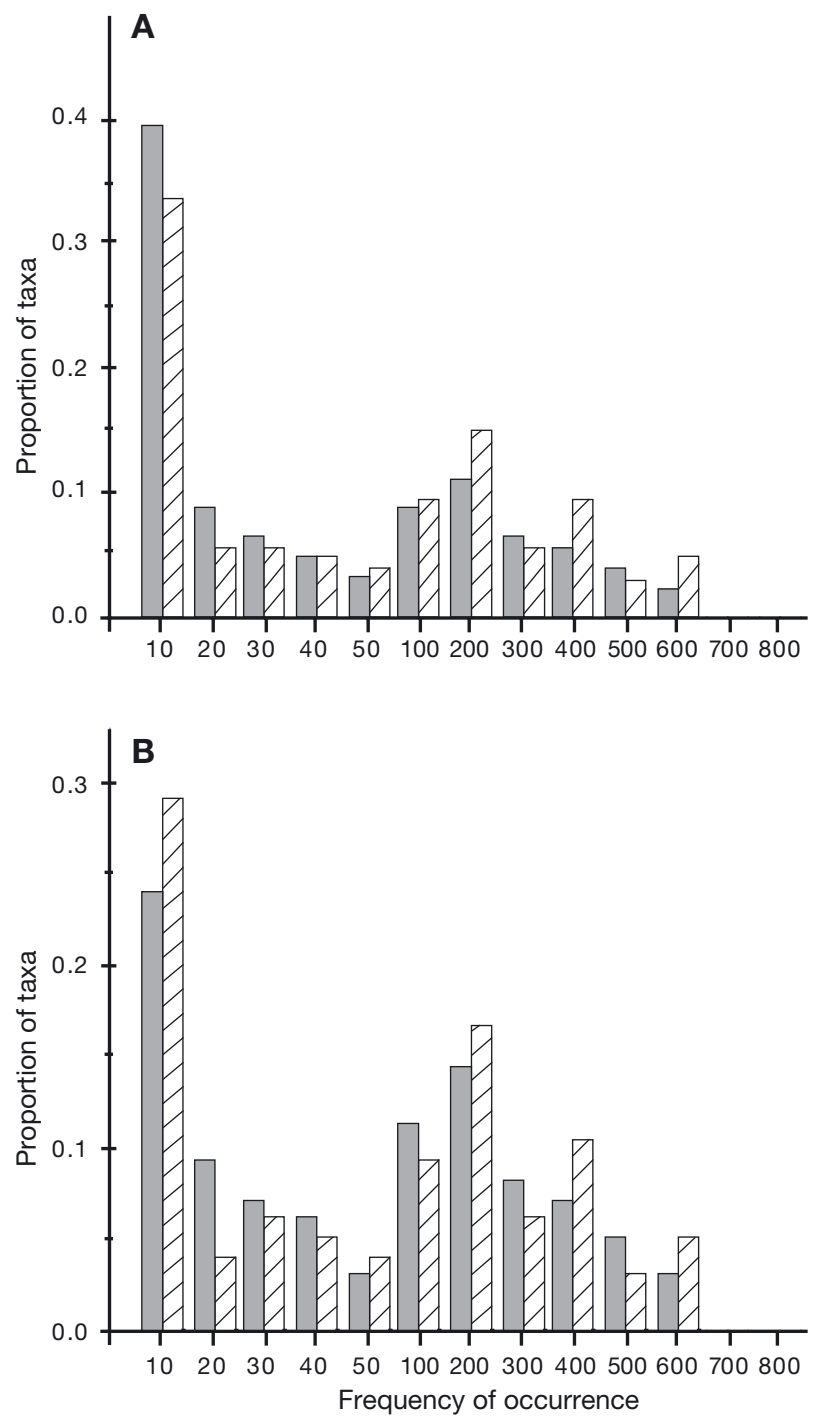

Fig. 2. Frequency of occurrence of (A) all taxa in each habitat and (B) those taxa common to both habitats in 800 quadrats (100 quadrats sampled at each height in each location). Solid bars: rocky shores; hatched bars: seawalls

pared using Kolmogorov-Smirnov tests (Fig. 2). Categories varied across the range because the study was most concerned with the rarer taxa. The frequency distributions were compared using Kolmogorov-Smirnov tests for all taxa (Fig. 2A), and the test was repeated when unique taxa were excluded (Fig. 2B). The latter tests for different patterns of occurrence for species that are found in both habitats.

There was a significant difference in the frequency distribution between habitats when all species were compared across all categories of distribution (Kolmogorov-Smirnov tests; $D=0.11 ; \mathrm{p}<0.05$; Fig. 2A) and when the particularly sparse taxa alone were compared (i.e. those found in 10 or fewer quadrats; $D=$ 0.24, p < 0,05; Fig. 3A). More taxa were found in fewer quadrats in rocky shores than on seawalls. When the common species were analysed, a different pattern was found. Over all categories of abundance, there was no significant difference in frequency $(D=0.03$; $\mathrm{p}>0.05$; Fig. 2B). When the sparse taxa alone were considered, again more occurred in few quadrats on the rocky shores than on the seawalls $(D=0.24 ; \mathrm{p}<$ 0.05; Fig. 3B).

The above analyses suggested that rocky shores should continue to accumulate more species as more of the area is sampled and more sparse species encountered, whereas seawalls should reach an asymptote more rapidly. Therefore, species-accumulation curves (Connor \& McCoy 1979) were compared between the 2 habitats for each height and location separately (using 100 quadrats). Combinations of quadrats for each
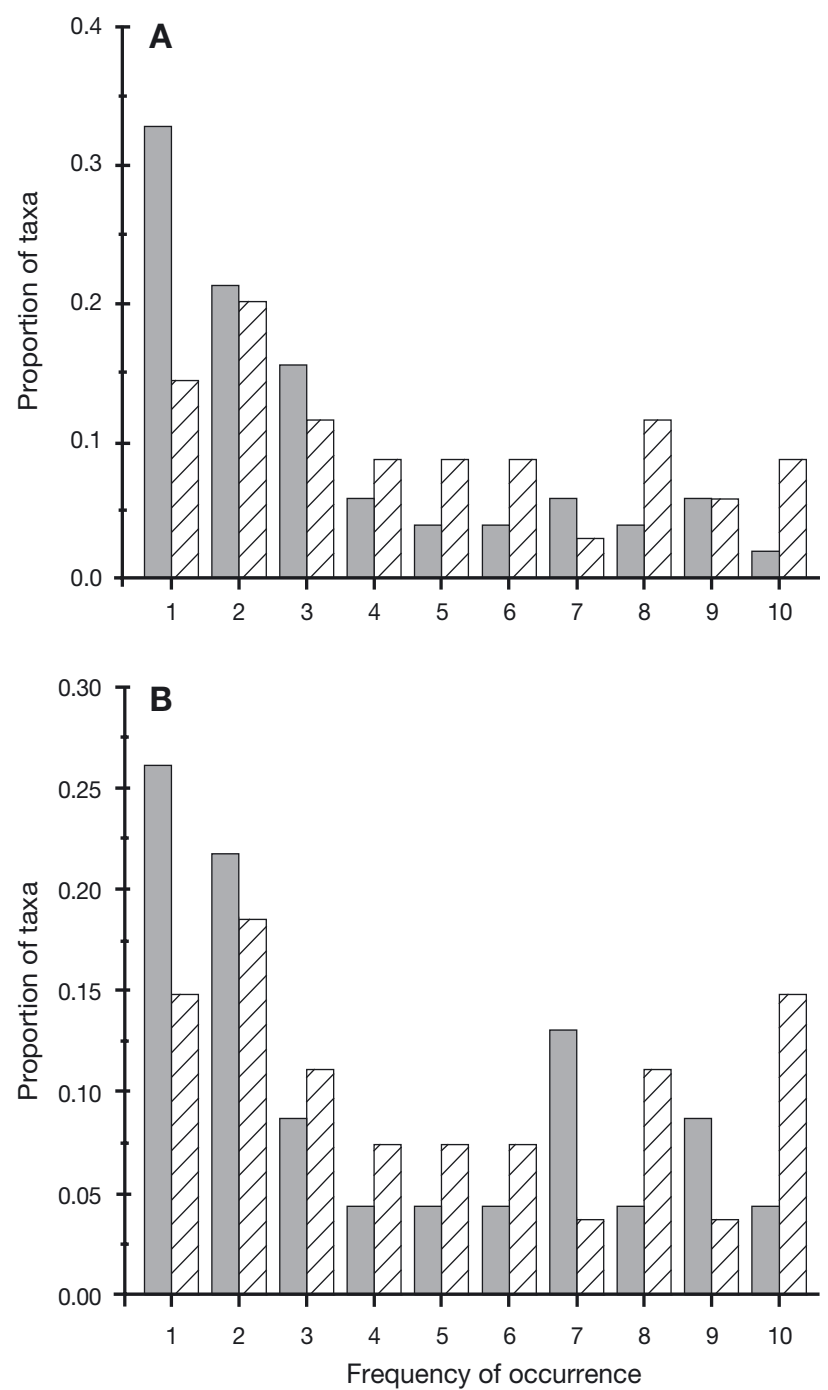

Fig. 3. Frequency of occurrence of (A) all taxa in each habitat and (B) those taxa common to both habitats which were only found in 1 to 10 quadrats (of the 800 quadrats sampled). Solid bars: rocky shores; hatched bars: seawalls 
sample-size were selected randomly to a maximum of 999 permutations for each sample size. As expected, from the previous patterns of variability among the different locations, there were no general patterns, with similar curves in some comparisons and faster rates of accumulation on either the seawall or the rocky shore in other locations. When data from both heights and all locations were combined, however, the numbers of taxa per habitat rapidly diverged (Fig. 4). Greater sampling intensity on rocky shores continued to accumulate more species than on seawalls and the rate of divergence continued as a larger area was sampled. Therefore, with greater sampling intensity, the difference in diversity between the rocky shores and seawalls increased.

Finally, to test the hypothesis that more species would be sampled when quadrats were spread over a greater extent of the rocky shore compared to those placed contiguously, this increase not being found on seawalls, species-accumulation curves and total number of taxa sampled were compared between 60 contiguous quadrats and 60 quadrats spaced over a greater distance for the mid-shore and low-shore assemblages separately in each location. It was not possible to combine data across locations because the pattern of spacing between quadrats varied among locations due to variation in the length or continuity of one of the habitats (see 'Materials and methods').

For the 8 comparisons on seawalls (2 heights in each of 4 locations), the spaced quadrats accumulated more species than the contiguous ones in 5 locations (Table $2 ; \mathrm{p}>0.05$ ), although differences were not very large. On the rocky shore, in contrast, the spaced quadrats accumulated more species than the contiguous quadrats in 7 of the 8 comparisons (Table $2 ; \mathrm{p}<$

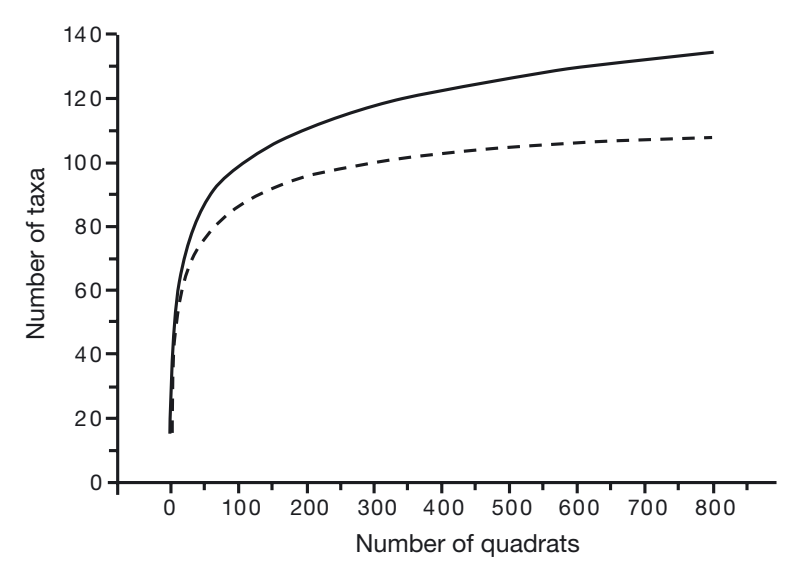

Fig. 4. Accumulation of taxa across 800 quadrats (100 quadrats sampled at each height in each location) for rocky shores (solid line) and seawalls (dashed line)
Table 2. Total number of taxa for 60 spaced (Sp.) or 60 contiguous (Cont.) quadrats for each height on each seawall and rocky shore

\begin{tabular}{|lcccccccc|}
\hline & \multicolumn{3}{c}{ Mid-shore } & \multicolumn{4}{c|}{ Low-shore } \\
& Seawall & Shore & \multicolumn{2}{c|}{ Seawall } & Shore \\
& Sp. Cont. & Sp. Cont. & Sp. Cont. Sp. Cont. \\
\hline Clark Island & 41 & 43 & 45 & 34 & 65 & 61 & 77 & 57 \\
Farm Cove & 43 & 44 & 52 & 51 & 66 & 65 & 51 & 49 \\
Kurraba Point & 50 & 50 & 50 & 43 & 50 & 45 & 64 & 56 \\
Little Manly & 43 & 42 & 64 & 63 & 60 & 54 & 75 & 79 \\
\hline
\end{tabular}

0.05). Increased spacing among quadrats appeared to have a stronger effect on species accumulation in low-shore compared to mid-shore levels in each habitat, although these differences were not significant.

\section{DISCUSSION}

There was considerable spatial variability in the diversity of species found on seawalls or rocky shores at different heights and in the 4 locations sampled. Neither the average number of taxa per quadrat, total number of taxa or the shape of the species-accumulation curves showed similar trends in differences between habitats for the 2 heights in any location. Locations were selected to be relatively undisturbed, with a gently sloping rocky shore adjacent to a sandstone seawall, but are representative of other similar locations in the vicinity. Large variation among locations is common on sheltered and wave-exposed shores in New South Wales (e.g. Underwood \& Chapman 1998) and has been shown previously for seawalls in the Harbour (Chapman \& Bulleri 2003). It may be explained by the relative ages of the seawalls (data are unavailable to test this model), by topographic complexity, other features of the different seawalls and/or variations in slope and complexity of the rocky shores (e.g. Glasby \& Connell 2001). Alternatively, wave-action or other hydrographic factors associated with the different locations may affect development of assemblages. Factors that may contribute to this variation are not discussed further, as they are not the main focus of this study.

When data for the different heights and locations were combined, however, there was a consistent difference between habitats. More taxa were found on rocky shores and this was primarily due to the numbers of mobile animals. Most algae (42 encrusting, filamentous and foliose algae) were found in both habitats, in contrast to studies showing greater abundances of common algae on horizontal surfaces (e.g. Kaehler \& Williams 1996, Goldberg \& Foster 2002). In this study, 
the few species of algae unique to one of the habitats were sparse, making up a very small component of the algal assemblage.

The sessile animals included bryozoans, tubiculous polychaetes, ascidians, sponges, barnacles, bivalves and sea anemones. Although approximately $40 \%$ of the 51 taxa found were unique to one or other of the habitats, sea anemones were the only group to show a consistent pattern. Taxa unique to seawalls included bivalves, sponges, bryozoans and ascidians, but many other species in these categories were common to both habitats, or only found on rocky shores. Again, many of these were sparse. Five species of sea anemones were found on rocky shores (as 55 occurrences in 800 quadrats), but only one of these, Actinia tenebrosa, was found on seawalls (only 3 occurrences). A. tenebrosa is a clonal sea anemone, commonly found amidst algae, in shallow depressions, rock-pools, overhangs and under intertidal boulders on rocky shores around Sydney. There have been no quantitative studies of recruitment and habitat-requirements for the other anemones found in this study (e.g. Oulactis mucosa, Cnidopus verater, Anthothoe albocincta, Corynactis australis), but preliminary data show that they are more restricted in habitat than are A. tenebrosa. They are generally found in pools or crevices that retain water during low tide (W. Green unpubl. data). Their absence from seawalls suggests that a microhabitat required by these animals is not present.

Mobile animals included grazing gastropods, opisthobranchs and pulmonate snails, limpets, predatory whelks, starfish, platyhelminths, sipunculids and one species of sea urchin. There were fewer species on seawalls than on rocky shores, although patterns varied among locations. Only limpets were found in similar frequencies in each habitat. Again, many of the taxa confined to rocky shores tended to be found in rock-pools, deep crevices or under thick algal cover or boulders (e.g. the urchin Heliocidaris eythrogramma, the whelks Cabestana spengleri and Bedeva hanleyi, the starfish Patiriella calcar and Coscinasterias calamaria and some of the rarer gastropods, such as Gena impertusa) - microhabitats that are generally absent from seawalls. Again, this suggests that the lack of these microhabitats may decrease the numbers of taxa that can use seawalls as intertidal habitat.

A previous study of intertidal seawalls, vertical rocky shores and sloping rock platforms showed greater differences in abundances of common taxa between seawalls and sloping shores than between seawalls and vertical shores and greater differences at mid-shore than at low-shore levels (Chapman \& Bulleri 2003), supporting Connell \& Glasby (1999), who showed little difference between subtidal assemblages on seawalls and vertical rock faces. In Chapman \& Bulleri (2003), differences between assemblages in the different habitats were primarily due to differences in the abundances of taxa common to the different habitats. Therefore, together with the present study, it appears that seawalls in Sydney Harbour support different intertidal assemblages from those found in natural habitats because of differences in the relative abundances of common taxa, the frequency of occurrence of sparse taxa, and because several mobile species are absent from seawalls.

These differences may be due to differences in recruitment and/or mortality. Recruitment of common taxa varies between seawalls and adjacent vertical rocky shores in Sydney Harbour (F. Bulleri pers. comm.) and this could not be correlated with slope (both habitats were vertical in F. Bulleri's study, unpubl.), nor surface-complexity (shown experimentally, F. Bulleri pers. comm.). Gastropods may preferentially recruit to small cracks or crevices on rocky shores (e.g. Fretter \& Manly 1977, Underwood \& Chapman 1992), but recruitment in response to slope or features of microhabitat has not been documented for many of the taxa that were uniquely found on rocky shores in the present study. It is still to be determined, therefore, whether the role of recruitment or subsequent mortality explains the patterns observed.

Whether differences are caused by recruitment or mortality, these data suggest that features of seawalls do not allow the natural range of mobile intertidal animals to live on these habitats. This may be due simply to slope, although the present study suggests that important microhabitats may be missing from seawalls. Many of the sparse mobile animals (excluding limpets) not found on seawalls are found in microhabitats that retain water, or remain damp during low tide, e.g. tidal pools, damp overhangs and crevices (the undersurfaces of small boulders).

Intertidal seawalls may thus be improved as intertidal habitats if they are (1) built in such a way as to add cavities that retain water during low tide and/or (2) are constructed with a more gentle slope or a combination of horizontal and vertical surfaces. These models can only be tested if the authorities responsible for building and maintaining seawalls are prepared to incorporate experiments into their engineering works, so that ecologists can collect the appropriate quantitative data. Fortunately, preliminary data indicate that the provision of small 'rock-pools' in vertical seawalls does supply habitat for species such as sea-hares, sea urchins and octopus. With the increasing conversion of natural shores to artificial habitats, understanding how to build such structures to maximize their ability to maintain natural biodiversity in urban environments must take priority, whilst simultaneously maintaining engineering and safety standards. 
Acknowledgements. I would like to thank the Research Support Staff, D. Blockley, A. Grigaliunus, S. Gartenstein, G. Kaplan, E. Lazzarotta, K. Mills, C. Myers, A. Palmer, V. Padula, R. Reinfrank and M. Wirth for assistance in the field and/or with data entry and checking. M. Holloway prompted this work by his parallel study in similar subtidal habitats. A. J. Underwood, as always, assisted greatly with ideas, comments and an evaluation of an earlier version of this manuscript. Funding was supplied by the Australian Research Council through its Special Research Centres Programme and the University of Sydney. Special thanks to North Sydney Municipal Council, Woollarah Municipal Council and John Thompson of John Nixon Pty. Ltd. for their support of this research. Three anonymous referees provided helpful critiques of an earlier draft of this manuscript.

\section{LITERATURE CITED}

Alig RJ, Healy RG (1987) Urban and built-up land area changes in the United States: an empirical investigation of determinants. Land Econ 63:215-226

Archambault P, Bourget E (1996) Scales of coastal heterogeneity and benthic intertidal species richness, diversity and abundance. Mar Ecol Prog Ser 136:111-121

Astles KL (1993) Patterns of abundance and distribution of species in intertidal rock pools. J Mar Biol Assoc UK 73: 555-569

Bastin L, Thomas CD (1999) The distribution of plant species in urban vegetation fragments. Landsc Ecol 14:493-507

Bell SS, Hall MO, Soffian S, Madley K (2002) Assessing the impact of boat propeller scars on fish and shrimp utilizing seagrass beds. Ecol Appl 12:206-217

Blair RB (1996) Land use and avian species diversity along an urban gradient. Ecol Appl 6:506-519

Bryan GW, Gibbs PE, Hummerstone LG, Burt GR (1986) The decline of the gastropod Nucella lapillus around southwest England: evidence for the effect of tributyl tin from antifouling plates. J Mar Biol Assoc UK 66:611-640

Bulleri F, Menconi M, Cinelli F, Benedetti-Cecchi L (2000) Grazing by two species of limpets on artificial reefs in the northwest Mediterranean. J Exp Mar Biol Ecol 255:1-19

Burdick DM, Short FT (1999) The effects of boat docks on eelgrass beds in coastal waters of Massachusetts. Environ Manag 23:231-240

Campbell S (2001) Ammonium requirements of fast-growing ephemeral macroalgae in a nutrient-enriched marine embayment (Port Phillip Bay, Australia). Mar Ecol Prog Ser 209:99-107

Chapman MG (2002) Patterns of spatial and temporal variation of macrofauna under boulders in a sheltered boulder field. Aust Ecol 27:211-228

Chapman MG, Bulleri F (2003) Intertidal seawalls-new features of landscape in intertidal environments. Landsc Urban Plann 62:159-172

Chapman MG, Underwood AJ, Skilleter GA (1995) Variability at different spatial scales between a subtidal assemblage exposed to the discharge of sewage and two control assemblages. J Exp Mar Biol Ecol 189:103-122

Connell SD (2000) Floating pontoons create novel habitats for subtidal epibiota. J Exp Mar Biol Ecol 247:183-194

Connell SD, Glasby TM (1999) Do urban structures influence local abundance and diversity of subtidal epibiota? A case study from Sydney Harbour, Australia. Mar Environ Res 47:373-387

Connor EF, McCoy ED (1979) The statistics and biology of the species-area relationship. Am Nat 113:791-833
Davis JLD, Levin LA, Walther SM (2002) Artificial armored shorelines: sites for open-coast species in a southern California bay. Mar Biol 140:1249-1262

Duarte CM (2002) The future of seagrass meadows. Environ Conserv 29:192-206

Eversham BC, Roy DB, Telfer MG (1996) Urban, industrial and other manmade sites as analogues of natural habitat for Carabidae. Ann Zool Fenn 33:149-156

Fretter V, Manly R (1977) The settlement and early benthic life of Littorina neritoides at Wembury, South Devon. J Molluscan Stud 43:255-262

Gabriele M, Bellet A, Gallotti D, Brunnetti R (1999) Sublittoral hard substrate communities of the northern Adriatic Sea. Cah Biol Mar 40:65-76

Gilbert F, Souchu P, Bianchi M, Bonin P (1997) Influence of shellfish farming activities on nitrification, nitrate reduction to ammonia and denitrification at the water-sediment interface of the Thau lagoon, France. Mar Ecol Prog Ser 151:143-153

Glasby TM (2000) Surface composition and orientation interact to affect subtidal epibiota. J Exp Mar Biol Ecol 248: $177-190$

Glasby TM, Connell SD (2001) Orientation and position of substrata have large effects on epibiotic assemblages. Mar Ecol Prog Ser 214:127-135

Goldberg NA, Foster MS (2002) Settlement and post-settlement processes limit the abundance of the geniculate coralline alga Calliarthron on subtidal walls. J Exp Mar Biol Ecol 278:31-45

Gray JS (1989) Effects of environmental stress on species rich assemblages. Biol J Linn Soc 37:19-32

Gray JS, Aschan M, Carr MR, Clarke KR, Green RH, Pearson TH, Rosenberg R, Warwick RM (1988) Analysis of community attributes of the benthic macrofauna of Frierfjord/ Langesundfjord and in a mesocosm experiment. Mar Ecol Prog Ser 46:151-165

Hawkins SJ, Hartnoll RG (1980) A study of the small-scale relationship between species number and area on a rocky shore. Estuar Coast Mar Sci 10:201-214

Inglis GI, Kross JE (2000) Evidence for systematic changes in the benthic fauna of tropical estuaries as a result of urbanization. Mar Pollut Bull 41:367-376

Johannesson K, Warmoes T (1990) Rapid colonization of Belgian breakwaters by the direct developer, Littorina saxatilis (Olivi) (Prosobranchia, Mollusca). Hydrobiologia 193:99-108

Kaehler S, Williams GA (1996) Distribution of algae on tropical rocky shores: spatial and temporal patterns of noncoralline encrusting algae in Hong Kong. Mar Biol 125: $177-187$

Kingsford MJ, Underwood AJ, Kennelly SJ (1991) Humans as predators on rocky reefs in New South Wales, Australia. Mar Ecol Prog Ser 72:1-14

McDonnell MJ, Pickett STA, Groffman P, Bohlen P and 5 others (1997) Ecosystem processes along an urban-to-rural gradient. Urban Ecosyst 1:21-36

McGuinness KA (1984) Species-area relations of communities on intertidal boulders: testing the null hypothesis. J Biogeogr 11:439-456

McGuinness KA (1989) Effects of some natural and artificial substrata on sessile marine organisms at Galeta Reef, Panama. Mar Ecol Prog Ser 52:21-28

McGuinness KA, Underwood AJ (1986) Habitat structure and the nature of communities on intertidal boulders. J Exp Mar Biol Ecol 104:97-123

Niemelä J (1999a) Ecology and urban planning. Biodivers Conserv 8:119-131 
Niemelä $J(1999 b)$ Is there a need for a theory of urban ecology? Urban Ecosyst 3:57-65

Nixon SW (1995) Coastal marine eutrophication-a definition, social causes, and future concerns. Ophelia 41: 199-219

Oliver I, Beattie AJ (1996) Invertebrate morphospecies as surrogates for species: a case study. Conserv Biol 10:99-109

Peterson CH, Kennicutt MC, Green RH, Montagna P, Harper DE, Powell EN, Roscigno PF (1996) Ecological consequences of environmental perturbations associated with offshore hydrocarbon production: a perspective on longterm exposures in the Gulf of Mexico. Can J Fish Aquat Sci 53:2637-2654

Raimondi PT (1988) Rock type affects settlement, recruitment, and zonation of the barnacle Chthamalus anisopoma Pilsbury. J Exp Mar Biol Ecol 123:253-268

Rebele F (1994) Urban ecology and special features of urban ecosystems. Global Ecol Biogeogr Lett 4:173-187

Saunders DA, Briggs SV (2002) Nature grows in straight lines-or does she? What are the consequences of the mismatch between human-imposed linear boundaries and ecosystem boundaries? An Australian example. Landsc Urban Plann 61:71-82

Savard JPL, Clergeau P, Mennechez G (2000) Biodiversity concepts and urban ecosystems. Landsc Urban Plann 48: 131-142

Short FT, Burdick DM (1996) Quantifying eelgrass habitat loss in relation to housing development and nitrogen loading in Waquoit Bay, Massachusetts. Estuaries 19:730-739

Smith AK, Ajani PA, Roberts DE (1999) Spatial and temporal variation in fish assemblages exposed to sewage and implications for management. Mar Environ Res 47: $241-260$

Squires MM, Lesack LFW (2001) Benthic algal response to pulsed versus distributed inputs of sediments and nutrients in a Mackenzie Delta lake. J N Am Benthol Soc 20: $369-384$

Stark JS (1998) Heavy metal pollution and macrobenthic assemblages in soft sediments in two Sydney estuaries, Australia. Mar Freshw Res 49:533-540

Thompson RC, Wilson BJ, Tobin ML, Hill AS, Hawkins SJ (1996) Biologically generated habitat provision and diversity of rocky shore organisms at a hierarchy of spatial scales. J Exp Mar Biol Ecol 202:73-84

Editorial responsibility: Roger Hughes (Contributing Editor), Bangor, UK
Thompson RC, Crowe TP, Hawkins SJ (2002) Rocky intertidal communities: past environmental changes, present status and predictions for the next 25 years. Environ Conserv 29: 168-191

Tyler G (1975) Heavy metal pollution and mineralization of nitrogen in forest soils. Nature 255:701-702

Underwood AJ (1981) Structure of a rocky intertidal community in New South Wales: patterns of vertical distribution and seasonal change. J Exp Mar Biol Ecol 51:57-85

Underwood AJ, Chapman MG (1998) Spatial analyses of intertidal assemblages on sheltered rocky shores. Aust J Ecol 23:138-157

Underwood AJ, Chapman MG (1999) Role of ecology in coastal zone management: perspectives from south-east Australia. In: Salomons W, Turner K, Lacerda LD, Ramachandran S (eds) Perspectives on integrated coastal zone management. Springer-Verlag, Berlin, p 99-128

van Herwenden L, Griffiths CL, Bally R, Blaine M, du Plessis C (1989) Patterns of shore utilization in a metroplitan area: The Cape Peninsula, South Africa. Ocean Shore Manag 12:331-346

Vidal M, Duarte CM, Sanchez MC (1999) Coastal eutrophication research in Europe: progress and imbalances. Mar Pollut Bull 38:851-854

Walker HJ (1988) Artificial structures and shorelines. Kluwer Academic Publishers, Los Angeles, CA

Walker DI, Laketelich RJ, Bastyan G, McComb AJ (1989) Effect of boat moorings on seagrass beds near Perth, Western Australia. Aquat Bot 36:69-77

Wendt PH, Knott DM, Van Doilah RF (1989) Community structure of the sessile biota onfive artificial reefs of different ages. Bull Mar Sci 44:1106-1122

Whitney GG, Adams SD (1980) Man as maker of new plant communities. J Appl Ecol 17:341-448

Whorff JS, Whorff LL, Sweet MH (1995) Spatial variation in an algal turf community with respect to substratum slope and wave height. J Mar Biol Assoc UK 75:429-444

Widmer WM, Underwood AJ, Chapman MG (2002) Public perception of potential environmental impacts of recreational boating in Sydney Harbour. Nat Res Manag 5:22-27

Zedler JB (1993) Lessons on preventing overexploitations. Ecol Appl 3:577-578

Zedler JB (1996) Coastal mitigation in southern California: the need for a regional restoration strategy. Ecol Appl 6:84-93

Submitted: January 9, 2003; Accepted: May 7, 2003

Proofs received from author(s): November 27, 2003 